\title{
Long-term disease-free survival in surgically-resected oral tongue cancer: a 10-year retrospective study
}

\author{
Sopravvivenza libera da malattia a lungo termine nel tumore della lingua mobile \\ operato: studio retrospettivo a 10 anni
}

\author{
A. MARRA ${ }^{1}$, M. VIOLATI' ${ }^{1}$ F. BROGGIO ${ }^{1}$, C. CODECÀ ${ }^{1}$, M. BLASI ${ }^{1}$, A. LUCIANI' ${ }^{1}$ S. ZONATO ${ }^{1}$, D. RABBIOSI ${ }^{2}$, \\ L. MONEGHINI ${ }^{3}$, A. SAIBENE ${ }^{4}$, A. MACCARI ${ }^{4}$, G. FELISATI ${ }^{4}$, D. FERRARI ${ }^{1}$ \\ ${ }^{1}$ Medical Oncology Unit, ${ }^{2}$ Maxillo-Facial Surgery Unit, ${ }^{3}$ Pathology Unit, ${ }^{4}$ Otolaryngology Unit, ASST Santi Paolo e \\ Carlo, University of Milan, Italy
}

\section{SUMMARY}

Early and loco-regionally advanced oral tongue squamous cell carcinoma (OTSCC) can be treated by surgery alone or followed by adjuvant radiotherapy or chemoradiotherapy. Nevertheless, up to $40 \%$ of patients develop tumour relapse. The aim of our study is to investigate the clinical and pathological features associated with reduced disease-free survival (DFS) in a cohort of surgically-resected OTSCC patients. One hundred and six patients surgically resected for OTSCC were retrospectively identified from clinical records. DFS was calculated according to the Kaplan-Meier method and differences between variables were assessed with Log-Rank test. A multivariable Cox regression model was used to analyse the impact of different prognostic factors on DFS. After a median of follow-up of 8.9 years, 22 events, including 11 deaths, were observed. Overall, the 5-year DFS-rate was $87.4 \%$. The presence of extra-nodal extension $(p=0.023)$ and perineural invasion $(p=0.003)$ were significantly correlated with shorter DFS (in univariate analysis). In multivariable analysis, extra-nodal extension and perineural invasion confirmed their role as independent prognostic factors associated with an increased risk of disease recurrence [hazard ratio (HR) 2.87, 95\% CI 1.11 - 7.42, p = 0.03; HR 3.85, 95\% CI $1.49-9.96, p=0.006$, respectively]. p16 and p53 expressions in tumour cells were detected in $12 \%(n=9)$ and $46 \%(n=40)$ of cases, respectively. No differences in DFS were observed between $\mathrm{p} 16+$ and $\mathrm{p} 16-(\mathrm{p}=0.125)$ and between $\mathrm{p} 53+$ and $\mathrm{p} 53$ - tumours $(\mathrm{p}=0.213)$. In conclusion, radical surgery, eventually followed by adjuvant radiotherapy or chemo-radiotherapy, can achieve high cure rates in OTSCC. After long-term follow-up, perineural invasion and extra-nodal extension confirmed their role as prognostic factors associated with reduced DFS in OTSCC patients.

KEY WORDS: Oral cancer • Tongue cancer • Head and neck squamous cell carcinoma • p53・p16

\section{RIASSUNTO}

Il tumore della lingua mobile, in fase iniziale o localmente avanzata, può essere trattato mediante chirurgia, da sola o seguita da radioterapia o chemio-radioterapia. Tuttavia, fino al $40 \%$ dei pazienti sviluppa una recidiva di malattia. Lo scopo del nostro studio è quello di valutare le caratteristiche anatomo-patologiche e cliniche associate ad una ridotta sopravvivenza libera da malattia (DFS) in pazienti con tumore della lingua mobile sottoposti a chirurgia. Sono stati identificati 106 pazienti operati per tumore della lingua mobile. Dopo un follow-up mediano di 8,9 anni, sono stati osservati 22 eventi, incluse 11 morti. Il tasso di DFS a 5 anni è stato dell'87,4\%. La presenza di estensione extranodale $(p=0,023)$ ed invasione perineurale $(p=0,003)$ erano significativamente correlate ad una DFS ridotta (analisi univariata). Nell'analisi multivariata, sia l'estensione extranodale che l'invasione perineurale hanno confermato il loro ruolo quali fattori prognostici associati ad un aumentato rischio di recidiva di malattia [Hazard Ratio (HR) 2,87, 95\% CI 1,11 - 7,42, p = 0,03; HR 3,85, 95\% CI 1,49 - 9,96, p=0,006]. L'espressione di p16 e p53 è stata identificata nel $12 \%(n=9)$ e 46\% $(n=40)$ dei casi, rispettivamente. Non sono state identificate differenze in termini di sopravvivenza tra tumori p53+e p53-, né tra tumori p16+ e p16-. In conclusione, la chirurgia primaria, eventualmente seguita da radioterapia o chemio-radioterapia, può consentire alti livelli di guarigione nel tumore della lingua mobile. L'invasione perineurale e l'estensione extra-nodale si sono confermati fattori prognostici correlati ad una minore DFS.

PAROLE CHIAVE: Tumori del cavo orale $\bullet$ Tumore della lingua $\bullet$ Tumori della testa e del collo $\bullet$ p53・p16

\section{Introduction}

Oral tongue squamous cell carcinoma (OTSCC) is the most common cancer diagnosed in the oral cavity, accounting for $25-40 \%$ of all oral malignancies ${ }^{1}$. In the United States, almost 17,000 new cases and 2,500 OTSCC-related deaths are expected in $2018^{2}$. OTSCC is burdened by significant morbidity and mortality and its incidence is continuously arising, particularly in young subjects ${ }^{34}$. Despite advances in detection and treatment, 5-year overall survival (OS) and disease-free survival (DFS) are steadily in the range of $50-60 \%{ }^{15}$. The pathogenesis of OTSCC is related to several factors involved 
in the carcinogenetic process such as heat, chronic injuries, poor oral hygiene, cigarette smoking and alcohol consumption ${ }^{6}$. Moreover, OTSCC is characterised by a high frequency of lymphatic metastasis, a high risk of recurrence and the possibility to develop drug resistance to chemotherapy during treatment ${ }^{7}$.

Clinical outcomes strictly correlate with disease stage and lymph node spread at the time of presentation. Moreover, some characteristics, such as tumour depth, vascular and perineural invasion (PNI) and tumour budding are widely recognised as prognostic factors ${ }^{8-13}$. Conversely, the impact on survival of other features, including anatomic site, age, tumour grade and some biological markers is still uncertain, depending on the great variability among reports in the literature, which is mainly represented by limited case series ${ }^{14}{ }^{15}$. A further confusing factor is the evaluation of oral tongue cancers either in series including base of tongue tumours or in series reporting a combination of cancers from different sites in the head and neck district. The management and outcomes of each subsite tend to be different ${ }^{16} 17$.

Surgery is the standard treatment for early OTSCC. Locally and loco-regionally advanced cases can be treated by surgery and adjuvant radiotherapy (RT) or chemoradiotherapy (CRT) according to the presence of risk factors such as lymph node metastases, extra-nodal extension (ENE) and involved surgical margins ${ }^{18}{ }^{19}$. Alternatively, primary concomitant CRT can be offered to patients with the aim of sparing organ function.

In this study, we retrospectively evaluated the role of surgery on clinical outcomes in a cohort of patients affected by OTSCC treated at our institution in the last decade.

\section{Materials and methods}

\section{Study setting}

This was a monocentric, retrospective, independent study on patients with surgically-resected OTSCC treated and followed at San Paolo Hospital (Milan, Italy) between July 2004 and December 2012. Demographic data, risk factors, tumour characteristics and disease status were obtained from medical records. The study was approved by local Ethics Committee. All patients alive at the time of data collection and/or analysis signed an informed consent for use of personal data.

All pathological specimens were reviewed by two independent pathologists to confirm diagnosis and evaluate tumour depth, grade of tumour cell differentiation, presence of perivascular invasion and PNI, marginal status and the presence of ENE. Tumour size and nodal involvement were categorised according to the American Joint
Committee on Cancer (AJCC) TNM staging ( $7^{\text {th }}$ Edition, 2009).

All cases were previously discussed and evaluated by a multidisciplinary team, consisting minimally of an oncologist, surgeon, radiotherapist, and dedicated radiologists and pathologists. Patients with localised or loco-regional disease were treated by radical surgery, consisting of tumour resection +/- lymph node neck dissection. The decision to proceed with lymph node neck dissection was taken after careful evaluation of nodal involvement at baseline imaging or as a consequence of pathological diagnosis. Patients with a tumour depth greater than $3 \mathrm{~mm}$ were deferred to elective neck dissection ${ }^{20}$. Patients with positive or close surgical margins, defined as the presence of tumour cells at the margin or within $5 \mathrm{~mm}$, received surgical re-intervention (whenever possible) or RT/CRT. Patients at risk of relapse (node metastases, ENE, critical margins) were treated with adjuvant RT or CRT, according to national and international guidelines ${ }^{1821}$.

Patients were then referred to the Oncology Unit for follow-up. Each follow-up visit included physical examination, blood tests and CT scan or MRI of the head and neck region (every 3 months during the first 2 years, and then every 6 to 12 months).

\section{Study population}

Eligibility criteria were: (1) age $\geq 18$ years; (2) pathologically confirmed diagnosis of resected OTSCC; (3) ECOG performance status (PS) of 0-2; (4) available data on risk factors, tumour characteristics and patient outcomes. Patients with (1) distant metastases at baseline imaging and/ or (2) primary tumour of the tongue base or other sites of the head and neck district were not included in the study.

\section{Objectives}

The main objective of the study was to investigate the impact of clinical and pathological characteristics on survival of patients with completely resected OTSCC. The primary endpoint was disease-free survival (DFS), defined as the time from surgery until the date of relapse, date of death or last follow-up visit, whichever occurred first. The secondary endpoint was overall survival (OS), defined as the time from surgery until the date of death.

\section{Immunohistochemistry for p16 and p53}

Immunohistochemistry (IHC) was performed according to standard protocols at our institution. Formalin-fixed, paraffin-embedded tissue sections $(4 \mu \mathrm{m})$ from OTSCC tumour samples were used as substrates in IHC reactions. IHC staining with monoclonal antibodies (mAbs) labeled for p16 $6^{\mathrm{INK} 4 \mathrm{~A}}$ (clone E6H4, Dako, Glostrup, Denmark) and 
p53 (clone DO-7, Thermo Fisher Scientific, MA, US) was performed, as previously described ${ }^{22}{ }^{23}$. Tumour slides were evaluated and classified by two pathologists. Positive p16 and p53 expressions were defined as the presence of strong and diffuse nuclear and cytoplasmic staining in more than $70 \%$ of tumour cells.

\section{Statistical analysis}

Demographic and clinical-pathological features were analysed using descriptive statistics. Absolute frequency and percentage were used to describe categorical variables, while median and interquartile range were reported for continuous variables. DFS was estimated using the Kaplan-Meier method and differences between variables were assessed with the Log-Rank test (univariate analysis). Cox proportional hazard regression models were used to evaluate the association between demographic and clinical-pathological variables and the survival endpoint. Statistical tests were two-sided and $p$-value less than 0.05 was considered as statistically significant. All the analyses were performed using SAS software v. 9.4 (SAS Institute, Cary, NC, US).

\section{Results}

Between July 2004 and December 2012, 106 OTSCC patients were included in the study. Patient characteristics are summarised in Table I.

Median age was 61 years (interquartile range $=51-69$ ). Sixty-eight patients $(64.1 \%)$ were male. Most patients presented with pT1 and pT2 disease $(\mathrm{n}=56,52.8 \%$, and $\mathrm{n}=31,29.2 \%$, respectively), while only a minority with pT3 and pT4 disease $(n=5,4.7 \%$, and $n=14,13.2 \%$, respectively). A tumour depth greater than $3 \mathrm{~mm}$ was found in 74 cases $(69.8 \%)$. Nodal involvement was detected in 37 patients (34.9\%), with the presence of ENE in 16 tumours $(15.1 \%)$. Tumours were well/moderately or poorly differentiated in $83(78.3 \%)$ and $23(21.7 \%)$ cases, respectively. PNI and perivascular invasions were detected in 13 $(12.2 \%)$ and $9(8.4 \%)$ tumours, respectively. Close or positive surgical margins were present in $17(16.0 \%)$ cases. Overall, 63 patients $(59.4 \%)$ were diagnosed with stage I or II disease, while stages III and IV were present in $14(13.2 \%)$ and 29 (27.4\%) cases, respectively. Regarding neck management, 82 patients $(77.3 \%)$ underwent neck dissection, concomitant to or deferred with respect to radical surgery. Sixty patients did not receive any postoperative treatment. Conversely, 27 (25.5\%) and 19 (17.9\%) patients received postoperative RTX or CRT, respectively, according to the presence of risk factors as previously described.
Table I. Baseline characteristics ( $N=106)$.

\begin{tabular}{|c|c|c|}
\hline & $\mathrm{N}$ & $\%$ \\
\hline \multicolumn{3}{|l|}{ Age } \\
\hline Median (IQR) & \multicolumn{2}{|c|}{$61(51-69)$} \\
\hline$<40$ years & 14 & 13.2 \\
\hline$\geq 40$ years & 92 & 86.8 \\
\hline \multicolumn{3}{|l|}{ Sex } \\
\hline Male & 68 & 64.1 \\
\hline Female & 38 & 35.9 \\
\hline \multicolumn{3}{|l|}{ Smoker } \\
\hline No & 31 & 29.2 \\
\hline Yes & 75 & 70.8 \\
\hline \multicolumn{3}{|l|}{ Neck dissection } \\
\hline No & 24 & 22.6 \\
\hline Yes & 82 & 77.4 \\
\hline \multicolumn{3}{|l|}{ Tumour } \\
\hline $\mathrm{pT} 1 / 2$ & 87 & 82.1 \\
\hline рT3/4 & 19 & 17.9 \\
\hline pT1 & 56 & 52.8 \\
\hline pT2 & 31 & 29.2 \\
\hline pT3 & 5 & 4.7 \\
\hline pT4 & 14 & 13.2 \\
\hline \multicolumn{3}{|l|}{ Node } \\
\hline $\mathrm{pNO} / \mathrm{X}$ & 69 & 65.1 \\
\hline $\mathrm{pN} 1 / 2 / 3$ & 37 & 34.9 \\
\hline pNX & 25 & 23.6 \\
\hline pNO & 44 & 41.5 \\
\hline $\mathrm{pN} 1$ & 13 & 12.3 \\
\hline pN2 & 23 & 21.7 \\
\hline pN3 & 1 & 0.9 \\
\hline \multicolumn{3}{|l|}{ Stage } \\
\hline$|/| \mid$ & 63 & 59.4 \\
\hline III/IV & 43 & 40.6 \\
\hline I & 46 & 43.4 \\
\hline$\|$ & 17 & 16.0 \\
\hline III & 14 & 13.2 \\
\hline IV & 29 & 27.4 \\
\hline \multicolumn{3}{|l|}{ ENE } \\
\hline Missing & 3 & 2.8 \\
\hline No & 87 & 82.1 \\
\hline Yes & 16 & 15.1 \\
\hline \multicolumn{3}{|l|}{ Depth } \\
\hline$<3 \mathrm{~mm}$ & 32 & 30.2 \\
\hline$\geq 3 \mathrm{~mm}$ & 74 & 69.8 \\
\hline \multicolumn{3}{|c|}{ Vascular invasion } \\
\hline Missing & 3 & 2.8 \\
\hline No & 94 & 88.7 \\
\hline Yes & 9 & 8.5 \\
\hline
\end{tabular}


Table I. follows.

\begin{tabular}{lcc} 
Perineural invasion & N & $\%$ \\
Missing & & \\
No & 3 & 2.8 \\
Yes & 90 & 84.9 \\
Tumour differentiation & 13 & 12.3 \\
G1/2 & & \\
G3 & 83 & 78.3 \\
Margins & 23 & 21.7 \\
No & & \\
Yes & 89 & 84.0 \\
Postoperative treatment & 17 & 16.0 \\
None & & \\
RT & 60 & 56.6 \\
CRT & 27 & 25.5 \\
\hline
\end{tabular}

CRT: chemo-radiotherapy ENE: extra-nodal extension; IQR: interquartile range; $R T$ : radiotherapy.

To evaluate any difference between age and clinicalpathological features, patients were subdivided into 2 age groups: $<40$ and $\geq 40$ years $(\mathrm{n}=14,13.21 \%$ and $\mathrm{n}=92$, $86.79 \%$, respectively). No significant differences in terms of tumour characteristics were observed between the two groups.

\section{Survival analysis}

Three patients were excluded from survival analysis due to the lack of information about the time of disease progression and/or death.

After a median of follow-up of 8.9 years (5.3 - 11.4), 22 $(21.4 \%)$ events occurred, including $11(10.7 \%)$ deaths (Table II).

In the first five years of follow-up, 13 tumour relapses, including 11 deaths, were observed. The 5-year DFS and OS rates were $87.4 \%$ and $91.3 \%$, respectively.

Using log-rank test, no significant differences in terms of DFS were observed for age groups $(p=0.222)$, smoking status ( $p=0.193)$, tumour size $(p=0.407)$, nodal involvement $(\mathrm{p}=0.379)$, tumour depth $(\mathrm{p}=0.161)$, vascular invasion $(p=0.291)$, tumour differentiation $(p=0.062)$ and surgical margins $(p=0.064)$. Conversely, the presence of ENE $(p=0.023)$ and PNI $(p=0.003)$ were significantly correlated with shorter DFS (Fig. 1).

In multivariable Cox regression analysis, the presence of ENE [Hazard Ratio (HR) 2.87, 95\% CI 1.11 7.42, $\mathrm{p}=0.03$ ] and PNI (HR 3.85, 95\% CI 1.49 - 9.96, $\mathrm{p}=0.006)$ were significantly associated with a higher risk of disease recurrence (Table III).

Regarding OS, in the multivariable Cox regression analysis, no significant differences were detected for age groups $(\mathrm{p}=0.837)$, smoking status $(\mathrm{p}=0.526)$, PNI $(\mathrm{p}=0.178)$, ENE $(p=0.961)$, nodal involvement $(p=0.553)$, tumour depth $(\mathrm{p}=0.515)$, tumour size $(\mathrm{P}=0.751)$, vascular invasion $(\mathrm{p}=0.753)$, tumour differentiation $(\mathrm{p}=0.087)$ and surgical margins $(p=0.702)$.

\section{Analysis for $p 16$ and p53 expressions}

Of the 106 tumours examined, 75 tissue samples were available for evaluation of $\mathrm{p} 16$ and $\mathrm{p} 53$ expression, which was present in $12 \%(n=9)$ and $46 \%(n=40)$ of the samples, respectively. However, no significant correlations with clinical features were observed.

In univariate analysis, no differences in terms of DFS and OS were observed between $\mathrm{p} 16+$ and $\mathrm{p} 16-(\mathrm{p}=0.125)$, as well as between $\mathrm{p} 53+$ and $\mathrm{p} 53$ - tumours $(\mathrm{p}=0.213)$.

\section{Discussion}

Radical surgery, eventually followed by RT or CRT, is the standard treatment for OTSCC leading to about a $70 \%$ probability of cure in the early stages ${ }^{18}$. Loco-regionally advanced disease still has a dismal prognosis and less than half of patients have a real chance of cure ${ }^{24}$. An integrated approach consisting of multimodality diagnostic and therapeutic workup is mandatory for high risk patients, defined by the presence of aggressive features such as advanced primary tumour (T3 or T4), number and sites of

Table II. DFS and OS events according to different stages of disease.

\begin{tabular}{|c|c|c|c|c|}
\hline \multirow[t]{2}{*}{ Stage } & \multicolumn{2}{|c|}{ DFS events } & \multicolumn{2}{|c|}{ OS events } \\
\hline & $\begin{array}{c}\text { No } \\
\text { N (\%) }\end{array}$ & $\begin{array}{c}\text { Yes } \\
\text { N (\%) }\end{array}$ & $\begin{array}{c}\text { No } \\
\text { N (\%) }\end{array}$ & $\begin{array}{c}\text { Yes } \\
\text { N (\%) }\end{array}$ \\
\hline | & 35 (33.9) & $10(9.7)$ & 42 (40.8) & $3(2.9)$ \\
\hline$\|$ & 15 (14.6) & $2(1.9)$ & $16(15.5)$ & $1(0.9)$ \\
\hline III & $11(10.7)$ & $1(0.9)$ & 12 (11.6) & $0(0.0)$ \\
\hline IV & 20 (19.4) & $9(8.7)$ & $22(21.4)$ & $7(6.9)$ \\
\hline Total & $81(78.6)$ & $22(21.4)$ & 92 (89.3) & $11(10.7)$ \\
\hline
\end{tabular}




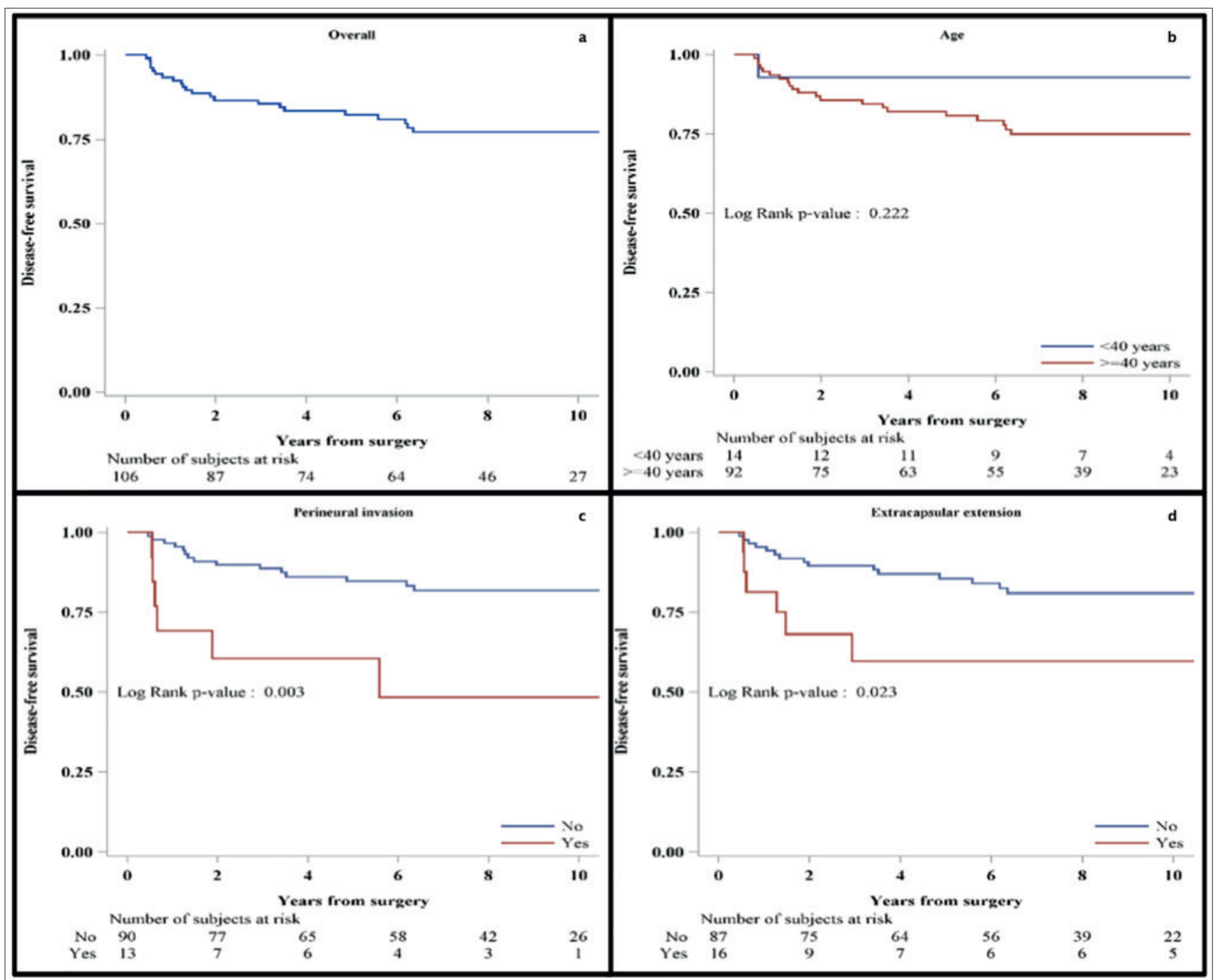

Fig. 1. Disease-free survival (DFS) in the overall population (a), and according to age (b), perineural invasion (c) and extracapsular extension (d).

lymph node involvement, ENE, PNI, vascular infiltration, poor tumour differentiation and incomplete surgery ${ }^{8-13}$. Although many studies have evaluated the role of multimodality treatment in head and neck cancers, only a few have focused on the impact of surgery and (chemo)radiation in tongue cancer exclusively.

We retrospectively analysed 106 OTSCC patients to identify risk factors associated with a reduced survival. The features of our population are in line with data available in the literature. Most of our patients had small tumours (especially pT1 and pT2), but nodal involvement was detected in about one-third of cases.

To detect differences in clinical-pathological features of disease presentation and recurrence, we subdivided the population in two cohorts in relation to age ( $<40$ and $\geq 40$ years). However, we found no difference between the two age groups. In the 14 patients in the youngest group, only one subject had disease recurrence in the observation period. We are aware that this could be related to the low percentage of young subjects in our population, nonetheless young age seems to consistently correlate with improved prognosis. Regarding survival differences between young and older OTSCC patients, contrasting data have been provided so far. Some authors reported that young subjects present worse survival outcomes than the elderly, justifying more intensive treatments in this subgroup ${ }^{25-28}$. Conversely, other studies demonstrated the absence of difference in terms of higher risk of disease recurrence or worse survival in young ( $<40$ years) OTSCC patients ${ }^{29}$. On the other hand, some authors have highlighted the role of aging in poor prognosis ${ }^{30}$ and the negative impact of comorbidities on elderly patients in terms of OS and postsurgical compli- 
Table III. Cox regression analysis for disease-free survival (DFS).

\begin{tabular}{|c|c|c|c|c|c|}
\hline & $\mathrm{N}$ & Events/PY & HR & $95 \% \mathrm{Cl}$ & P-value \\
\hline \multicolumn{6}{|l|}{ Age } \\
\hline$<40$ years & 14 & $1 / 106$ & \multirow{2}{*}{3.26} & \multirow{2}{*}{$0.44-24.23$} & \multirow{2}{*}{0.25} \\
\hline$\geq 40$ years & 92 & $21 / 625$ & & & \\
\hline \multicolumn{6}{|l|}{ Smoker } \\
\hline No & 31 & $4 / 240$ & \multirow{2}{*}{2.03} & \multirow{2}{*}{ 0.69-5.99 } & \multirow{2}{*}{0.20} \\
\hline Yes & 75 & $18 / 491$ & & & \\
\hline \multicolumn{6}{|l|}{ pT } \\
\hline $\mathrm{pT} 1 / 2$ & 87 & $17 / 620$ & \multirow{2}{*}{1.52} & \multirow{2}{*}{$0.56-4.13$} & \multirow{2}{*}{0.41} \\
\hline pT3/4 & 19 & $5 / 112$ & & & \\
\hline \multicolumn{6}{|l|}{$\mathrm{pN}$} \\
\hline $\mathrm{pNO} / \mathrm{X}$ & 69 & $13 / 498$ & \multirow{2}{*}{1.46} & \multirow{2}{*}{$0.62-3.42$} & \multirow{2}{*}{0.38} \\
\hline $\mathrm{pN} 1 / 2 / 3$ & 37 & $9 / 234$ & & & \\
\hline \multicolumn{6}{|l|}{ ENE $^{*}$} \\
\hline No & 87 & $15 / 625$ & \multirow{2}{*}{2.87} & \multirow{2}{*}{$1.11-7.42$} & \multirow{2}{*}{0.03} \\
\hline Yes & 16 & $6 / 86$ & & & \\
\hline \multicolumn{6}{|l|}{ Depth } \\
\hline$<3$ & 32 & $4 / 245$ & \multirow{2}{*}{2.13} & \multirow{2}{*}{$0.72-6.30$} & \multirow{2}{*}{0.17} \\
\hline$\geq 3$ & 74 & $18 / 487$ & & & \\
\hline \multicolumn{6}{|c|}{ Vascular invasion* } \\
\hline No & 94 & $18 / 657$ & \multirow{2}{*}{1.91} & \multirow{2}{*}{$0.56-6.50$} & \multirow{2}{*}{0.30} \\
\hline Yes & 9 & $3 / 54$ & & & \\
\hline \multicolumn{6}{|c|}{ Perineural invasion* } \\
\hline No & 90 & $15 / 652$ & \multirow{2}{*}{3.85} & \multirow{2}{*}{$1.49-9.96$} & 006 \\
\hline Yes & 13 & $6 / 59$ & & & 0.000 \\
\hline Grading & & & & & \\
\hline $\mathrm{G} 1 / 2$ & 83 & $14 / 591$ & 224 & $094-534$ & 0.07 \\
\hline G3 & 23 & $8 / 141$ & $2 . \angle 4$ & $0.04-0.04$ & 0.01 \\
\hline Margins & & & & & \\
\hline No & 89 & $16 / 645$ & 238 & $0.93-611$ & 007 \\
\hline Yes & 17 & $6 / 86$ & 2.38 & $0.93-6.11$ & 0.07 \\
\hline
\end{tabular}

* 3 patients with missing information. Cl: confidence interval; HR: hazard ratio; ENE: extra-nodal extension; PY: per-year.

cations ${ }^{31}$. However, these latter studies were not focused on OTSCC, but included patients with tumours at different head and neck sites. Therefore, the impact of age on OTSCC prognosis has not been well defined and further studies that address this issue are warranted.

In our population, 5-year DFS and OS rates were $87.4 \%$ and $91.3 \%$, respectively. These encouraging survival outcomes could be attributed to the post-operative strategies adopted, such as neck dissection and RT or CRT for patients displaying major risk factors. As previously described, patients with tumour depth greater than $3 \mathrm{~mm}$ were referred to elective neck dissection ${ }^{20}$ as well as those with positive surgical margins, who received surgical reintervention or, if technically not feasible, adjuvant CRT.
In addition, the presence of ENE was a further absolute indication to adjuvant CRT. Patients with minor risk factors such as pT3 or pT4 primary, N2 or N3 nodal disease, nodal disease in levels IV or V, PNI, vascular embolism or lymphatic invasion underwent adjuvant RTX ${ }^{1821}$. We did not find any difference in terms of DFS when considering smoking status, tumour size, nodal involvement, tumour depth, vascular invasion, positive surgical margins and cell differentiation.

Moreover, our study did not demonstrate a link between p16 expression and survival, confirming that the prognostic role of human papilloma virus (HPV) infection in OTSCC is not yet clear ${ }^{32} 33$. In addition, p53 expression did not impact on survival. Thus, our study is in good 
agreement with the recent meta-analysis by Almangush et al., suggesting that $\mathrm{p} 16$ and $\mathrm{p} 53$ expression have no role as prognostic factors in OTSCC ${ }^{34}$, while their pathogenetic role is unanimously recognised in oropharyngeal cancer ${ }^{35}{ }^{36}$. To date, no clear prognostic biomarker has been established for OTSCC patients treated with radical surgery. Ongoing research on new biomarkers and genomic determinants might allow better understanding of the factors involved in OTSCC pathogenesis and progression ${ }^{37} 38$.

Notably, tumours presenting with PNI had a higher risk of disease recurrence. PNI has a well-recognised prognostic role and is associated with dismal prognosis in head and neck tumours ${ }^{39}{ }^{40}$. The presence of ENE also indicates an increased risk of tumour relapse, confirming its role as an independent poor prognostic factor ${ }^{41}$.

Nowadays, high-quality surgery, eventually followed by RTX or CRT according to the presence of risk factors, represents the cornerstone on which long survival of early stage OTSCC is based. As previously described, in our population tumours with PNI and ENE presented a higher risk of disease relapse, underlining their significant role as prognostic factors. Moreover, their presence in tissue samples highlights the need of a careful multidisciplinary evaluation in order to plan the best postoperative therapeutic strategies.

\section{Conclusions}

Our study, with the limitation of a retrospective analysis, highlights the possibility to achieve high cure rates in OTSCC. PNI and ENE were independently associated with reduced DFS in our population. Survival rates of around $90 \%$ can be achieved by strict cooperation of a multidisciplinary team of experts that manages the patient from the first diagnostic approach to completion of treatment and definition of proper follow-up.

\section{Conflict of interest statement}

None declared.

\section{References}

1 Bello IO, Soini Y, Salo T. Prognostic evaluation of oral tongue cancer: means, markers and perspectives (I). Oral Oncol 2010;46:630-5.

2 Siegel RL, Miller KD, Jemal A. Cancer statistics, 2018. CA Cancer J Clin 2018;68:7-30.

3 Patel SC, Carpenter WR, Tyree S, et al. Increasing incidence of oral tongue squamous cell carcinoma in young white women, age 18 to 44 years. J Clin Oncol 2011;29:1488-94.

$4 \mathrm{Ng} \mathrm{JH}$, Iyer NG, Tan MH, et al. Changing epidemiology of oral squamous cell carcinoma of the tongue: a global study. Head Neck 2017;39:297-304.

5 van Dijk BA, Brands MT, Geurts SM, et al. Trends in oral cavity cancer incidence, mortality, survival and treatment in the Netherlands. Int J Cancer 2016;139:574-83.

6 Ram H, Sarkar J, Kumar H, et al. Oral cancer: risk factors and molecular pathogenesis. J Maxillofac Oral Surg 2011;10:132-7.

7 Han G, Xu C, Yu D. Mechanisms correlated with chemotherapy resistance in tongue cancers. J Cancer Res Ther 2018;14:1-5.

8 Asakage T, Yokose T, Mukai K, et al. Tumor thickness predicts cervical metastasis in patients with stage I/II carcinoma of the tongue. Cancer 1998;82:1443-8.

9 Po Wing Yuen A, Lam KY, Lam LK, et al. Prognostic factors of clinically stage I and II oral tongue carcinoma-A comparative study of stage, thickness, shape, growth pattern, invasive front malignancy grading, Martinez-Gimeno score, and pathologic features. Head Neck 2002;24:513-20.

10 Brown B, Barnes L, Mazariegos J, et al. Prognostic factors in mobile tongue and floor of mouth carcinoma. Cancer 1989;64:1195-202.

11 Bonnardot L, Bardet E, Steichen O, et al. Prognostic factors for T1T2 squamous cell carcinomas of the mobile tongue: a retrospective cohort study. Head Neck 2011;33:928-34.

12 Huang SH, Hwang D, Lockwood G, et al. Predictive value of tumor thickness for cervical lymph-node involvement in squamous cell carcinoma of the oral cavity: a meta-analysis of reported studies. Cancer 2009;115:1489-97.

13 Sakata J, Yamana K, Yoshida R, et al. Tumor budding as a novel predictor of occult metastasis in cT2NO tongue squamous cell carcinoma. Hum Pathol 2018;76:1-8.

14 Bello IO, Soini Y, Salo T. Prognostic evaluation of oral tongue cancer: means, markers and perspectives (II). Oral Oncol 2010;46:636-43.

15 Cracchiolo JR, Xu B, Migliacci JC, et al. Patterns of recurrence in oral tongue cancer with perineural invasion. Head Neck 2018;40:1287-95.

16 Maddox WA, Sherlock EC, Evans WB. Cancer of the tongue: review of thirteen-year experience - 1955-1968. Am Surg 1971;37:624-50.

17 Zelefsky MJ, Harrison LB, Fass DE, et al. Postoperative radiotherapy for oral cavity cancers: impact of anatomic subsite on treatment outcome. Head Neck 1990;12:470-5.

18 Gregoire V, Lefebvre JL, Licitra L, et al. Squamous cell carcinoma of the head and neck: EHNS-ESMO-ESTRO Clinical Practice Guidelines for diagnosis, treatment and follow-up. Ann Oncol 2010;21(Suppl 5):v184-6.

19 D'Cruz AK, Vaish R, Kapre N, et al. Elective versus therapeutic neck dissection in node-negative oral cancer. $\mathrm{N}$ Engl $\mathrm{J}$ Med 2015;373:521-9.

20 Civantos FJ, Zitsch RP, Schuller DE, et al. Sentinel lymph node biopsy accurately stages the regional lymph nodes for T1-T2 oral squamous cell carcinomas: results of a prospective multi-institutional trial. J Clin Oncol 2010;28:1395-400.

21 Network NCC. Head and Neck Cancers, Version 2.2018. Available at: https://www.ncen.org/professionals/physician_gls/pdf/head-andneck.pdf. Accessed 16 August, 2018.

22 Lim AM, Do H, Young RJ, et al. Differential mechanisms of CDKN2A (p16) alteration in oral tongue squamous cell carcinomas and correlation with patient outcome. Int J Cancer 2014;135:887-95.

23 Xie X, Clausen OP, De Angelis $\mathrm{P}$, et al. The prognostic value of spontaneous apoptosis, Bax, Bcl-2, and p53 in oral squamous cell carcinoma of the tongue. Cancer 1999;86:913-20.

24. Rusthoven K, Ballonoff A, Raben D, et al. Poor prognosis in pa- 
tients with stage I and II oral tongue squamous cell carcinoma. Cancer 2008;112:345-51.

25 Jeon JH, Kim MG, Park JY, et al. Analysis of the outcome of young age tongue squamous cell carcinoma. Maxillofac Plast Reconstr Surg 2017;39:41.

26 Zhang YY, Wang DC, Su JZ, et al. Clinicopathological characteristics and outcomes of squamous cell carcinoma of the tongue in different age groups. Head Neck 2017;39:2276-82.

27 Hilly O, Shkedy Y, Hod R, et al. Carcinoma of the oral tongue in patients younger than 30 years: comparison with patients older than 60 years. Oral Oncol 2013;49:987-90.

28 Park JO, Sun DI, Cho KJ, et al. Clinical outcome of squamous cell carcinoma of the tongue in young patients: a stage-matched comparative analysis. Clin Exp Otorhinolaryngol 2010;3:161-5.

29 Tsai MS, Lai CH, Lee CP, et al. Mortality in tongue cancer patients treated by curative surgery: a retrospective cohort study from CGRD. Peer J 2016;4:e2794.

30 Cadoni G, Giraldi L, Petrelli L, et al. Prognostic factors in head and neck cancer: a 10-year retrospective analysis in a single-institution in Italy. Acta Otorhinolaryngol Ital 2017;37:458-66.

31 Molteni G, Valerini S, Alicandri-Ciufelli M, et al. Unravelling the risk factors that underlie oral and oropharyngeal surgery in elderly. Acta Otorhinolaryngol Ital 2018;38:409-16.

32 Minami K, Kogashiwa Y, Ebihara Y, et al. Human papillomavirus and p16 protein expression as prognostic biomarkers in mobile tongue cancer. Acta Otolaryngol 2017;137:1121-6.

33 Liang XH, Lewis J, Foote R, et al. Prevalence and significance of human papillomavirus in oral tongue cancer: the Mayo Clinic experience. J Oral Maxillofac Surg 2008;66:1875-80.

34 Almangush A, Heikkinen I, Makitie AA, et al. Prognostic biomarkers for oral tongue squamous cell carcinoma: a systematic review and meta-analysis. Br J Cancer 2017;117:856-66.

35 Elrefaey S, Massaro MA, Chiocca S, et al. HPV in oropharyngeal cancer: the basics to know in clinical practice. Acta Otorhinolaryngol Ital 2014;34:299-309.

36 Ang KK, Harris J, Wheeler R, et al. Human papillomavirus and survival of patients with oropharyngeal cancer. $\mathrm{N}$ Engl $\mathrm{J}$ Med 2010;363:24-35.

37 Kang H, Kiess A, Chung CH. Emerging biomarkers in head and neck cancer in the era of genomics. Nat Rev Clin Oncol 2015;12:11-26.

38 Arantes L, De Carvalho AC, Melendez ME, et al. Serum, plasma and saliva biomarkers for head and neck cancer. Expert Rev Mol Diagn 2018;18:85-112.

39 Tai SK, Li WY, Yang MH, et al. Perineural invasion as a major determinant for the aggressiveness associated with increased tumor thickness in t1-2 oral tongue and buccal squamous cell carcinoma. Ann Surg Oncol 2013;20:3568-74.

40 Liu SA, Wang CC, Jiang RS, et al. Pathological features and their prognostic impacts on oral cavity cancer patients among different subsites - A singe institute's experience in Taiwan. Sci Rep 2017;7:7451.

41 Matsumoto F, Mori T, Matsumura S, et al. Prognostic significance of surgical extranodal extension in head and neck squamous cell carcinoma patients. Jpn J Clin Oncol 2017;47:699-704.

Received: September 17, 2018 - Accepted: November 29, 2018

How to cite this article: Marra A, Violati M, Broggio F, et al. Long-term disease-free survival in surgically-resected oral tongue cancer: a 10-year retrospective study. Acta Otorhinolaryngol Ital 2019;39:84-91. https://doi.org/10.14639/0392-100X-2336

Address for correspondence: Daris Ferrari, Medical Oncology Unit, ASST Santi Paolo e Carlo, University of Milan, via Antonio di Rudinì 8, 20142 Milan, Italy. Tel. +39 02 81844493. E-mail: daris.ferrari@asst.santipaolocarlo.it 